\title{
Persons affected by leprosy and the COVID-19 global health crisis: a consultative calls report from GPZL's emergency response Working Group 2
}

\author{
Andie Tucker, Alice Cruz, Mathias Duck \& Amar Timalsina, On \\ behalf of The Global Community of Persons Affected by Hansen's \\ disease/leprosy
}

Submitted and accepted 16 November 2020

\section{Introduction}

The COVID-19 pandemic has impacted leprosy control and prevention and persons affected by leprosy. The Global Partnership for Zero Leprosy (GPZL) established emergency response working groups in April 2020 to address key challenges during the pandemic.

The Emergency Response Working Group Two organized regional calls for persons affected and representative organizations to identify their needs and challenges. Data compiled in this report reflects the generous contributions of persons affected. The Emergency Response Working Group Two is grateful for their assistance and recognizes the call participants as creators of this report. The appendix lists the organizations of persons affected that contributed to these calls.

\section{Summary}

The objective of the consultative calls was to identify specific needs and challenges of persons affected by leprosy during the COVID-19 pandemic. The following issues were raised on a consistent basis: access to health care, fundamental goods, government support, stable livelihoods, information about COVID-19, and challenges due to intersecting vulnerabilities.

\section{Methods}

The Emergency Response Working Group Two conducted seven consultative calls with individuals and organizations of persons affected, from April to May 2020, speaking with over 100 individuals from more than 25 organizations from 22 different countries. The first six calls were organized by region. To increase representation of women's voices, the final call was for women affected. Guiding questions explored the access to services, information, and fundamental goods, populations that are more vulnerable to the impact of COVID-19, the

Correspondence to: Andie Tucker (e-mail: atucker@taskforce.org) 
current reality in Hansen's disease settlements, and communication strategies. Each call was facilitated by a person affected on Zoom.

\section{Results}

COVID-19 IMPACT ON ACCESS TO LEPROSY-RELATED HEALTH SERVICES

\section{Access to health facilities and medical care}

Persons affected have ongoing leprosy-related healthcare needs. Access to healthcare and health facilities is limited by transportation bans. When able to reach health facilities, they face reductions in services. MDT is largely still available, but reaction treatment is unobtainable for many.

\section{Wound care}

Persons affected by leprosy require continued medical care, especially for leprosy-related wounds, reactions, and disabilities. This has long-term impacts on their health and could lead to an increase in leprosy-related disability.

\section{Drug provision (MDT and reaction treatment medication)}

National Leprosy Programmes in many of the countries represented on the consultative calls are distributing three months of Multi Drug Therapy (MDT) to patients at a time to reduce patient visits to collect medication. In some countries, there was less certainty for patients that collect medication at government health facilities. Closure of government health facilities to leprosy patients is likely preventing some patients from receiving MDT. No call attendees reported that reaction treatment drugs were available for more than a month at a time for patients under reaction management.

\section{ACCESS TO SOCIAL PROTECTION SERVICES FOR PERSONS AFFECTED}

In most countries represented on the calls, food aid, income support, and other key social protection services are reaching some persons affected, but many are unable to benefit from it because of structural barriers, transportation challenges, or information gaps. Persons affected are relying on a patchwork safety net of services from governments and NGOs, but it is unclear who is receiving what, and difficult to ensure that everyone's needs are met.

\section{COVID-19 IMPACT ON ACCESS TO FUNDAMENTAL GOODS}

Persons affected are facing difficulty obtaining basic goods, especially food, clean water and soap, which are critical to fighting COVID-19. Lost livelihoods and travel restrictions have made it difficult to obtain food, and many communities and settlements of persons affected have not had access to clean water prior to the pandemic - a preexisting vulnerability that has been exacerbated by the current crisis.

\section{LIVELIHOODS}

Persons affected often work in the informal economy and are particularly vulnerable to economic instability. Many persons affected are unable to work. Their ability to meet basic needs is in severe jeopardy. 
COVID-19 FURTHER COMPOUNDS PREEXISTING INTERSECTING VULNERABILITIES

Persons affected face vulnerabilities in addition to their health status. The intersections of these vulnerabilities are key considerations that should inform the approach to support persons affected during the COVID-19 pandemic.

Age

In many countries, like Indonesia and Japan, the majority of persons affected are elderly. Their age puts them at greater risk of infection with COVID-19 and prevents them from accessing important supportive care services and goods. In Indonesia, elderly persons affected often do not have identity cards, so they are not eligible to receive government food aid, and technology and educational barriers restrict their access to telehealth resources.

\section{Gender}

Many women expressed their concern that the burdens of health protection, education and maintenance of family life were falling heavily on women affected during this crisis. Concern was expressed that women, who already work the 'double shift' of employment both outside and inside the home, were bearing more responsibilities during the pandemic because of the cancellation of supportive care services. Concern for women's increased responsibility for income generation, as well as an increase in domestic violence, was also expressed.

\section{Race}

Race was discussed by one call member as a compounding vulnerability in Brazil during the COVID-19 pandemic. The point was made that Black people are already particularly vulnerable to racial stigma and discrimination, resulting in the worst health outcomes of any group in the country for leprosy care. Disability rates are higher among the Black population in Brazil. Persons affected that are in a racial minority are even more vulnerable to negative health outcomes related to leprosy, and to the impacts of this pandemic.

\section{Health-related stigma}

Persons affected by leprosy face extreme health-related stigma, impacting the way they receive services and assistance during the pandemic. Persons affected from Nepal reported that when seeking pandemic aid, they often receive less assistance than those that have not been diagnosed with leprosy. In Indonesia, stigma against persons affected by leprosy intersects with an increasing stigma against people affected by COVID-19. If a person affected were to contract COVID-19, the compounded stigma may prevent them or their family from receiving assistance.

\section{Mental health challenges}

Persons affected have deep personal experience with quarantining, isolation, loneliness, lost livelihoods, and fear of transmission. Some call participants described the trauma of reliving their experience of being isolated because of leprosy. Others expressed the pain of not being able to support their friends that are persons affected. Organizations of persons affected and their partners are leading the response to the mental health challenges that have arisen in the global community of persons affected.

\section{Government inattention to the particular health vulnerabilities of persons affected}

Through both action and inaction, governments can protect or endanger the health of persons affected during the pandemic. Some governments are bolstering the isolation of settlements or 
communities of persons affected to keep them insulated from COVID-19 cases. In some cases, this heightened isolation has increased mental health risks. However, the measure guards the physical health of persons affected, who may be immunocompromised and more susceptible to COVID-19 infection. In other countries, governments are placing persons affected at greater risk of COVID-19 infection, by using leprosy health facilities as COVID-19 treatment centers.

\section{COVID-19 IMPACT ON EXISTING LEPROSY SETTLEMENTS}

Representatives from countries that have leprosy settlements, like Japan, reported that leprosy sanatoriums have been isolated from the public to prevent COVID-19 exposure. Although residents receive care from the sanatorium staff, isolation has impacted their mental wellbeing. There have been some reported COVID-19 cases in some leprosy settlements in India, and none reported in others. Settlements are supported by a patchwork of aid from the government, NGOs, and private donors, but it is unclear whether all needs are being met. In Ethiopia leprosy settlements with no cases of COVID-19, poor living conditions and limited access to power and clean water raise concern that COVID-19 would be difficult to mitigate.

\section{ACCESS TO INFORMATION ABOUT COVID-19}

Although some persons affected receive health promotion information, others do not due to travel restrictions, geography, or illiteracy. Organizations of persons affected and NGOs are finding alternative ways to get messages to those that need them.

\section{Discussion}

Emergency Response Working Group Two's consultative calls aimed to identify specific needs and challenges of persons affected by leprosy during the COVID-19 pandemic. The issues explored highlight the particular vulnerability of persons affected during the pandemic and raise key issues to be addressed by the members of GPZL, NGOs leaders, inter-governmental agencies, and government leaders.

While the COVID-19 pandemic has led to new challenges for persons affected by leprosy, such as limited transportation, it has also compounded issues that persons affected faced beforehand, such as stigma and discrimination and limited access to clean water. Many problems are still underdocumented, such as long-term effects on mental well-being as a result of isolation and intersecting vulnerabilities. GPZL's Emergency Response Working Group Three aims to plan for the leprosy community in a post-COVID-19 world. Certainly, COVID-19 has exposed existing health and economic disparities around the world. As a result, governments and NGOs must shift their attention to building stronger social safety nets that will support persons affected by leprosy and other vulnerable populations.

\section{Appendix A}

Organizations of persons affected consulted via regional calls and written submissions:

- APAL, India

- ASOCIACIÓN PACIENTES CON MAL DE HANSEN DE LORETO, San Pablo de Loreto, Peru

- ASOHANVIDA (Asociación de Personas Afectadas por Hansen Luz y Vida), Santiago de Cali, Colombia

- Coalition of Leprosy Advocates of the Philippines (CLAP), the Philippines

- ENAPAL, Addis Ababa, Ethiopia 
- Felehansen, Bogotá, Colombia

- Global Leprosy Champions

- HANDA, China

- IDEA Ghana

- IDEA India

- IDEA Kenya

- IDEA Nepal

- Kripaon Ki Mata (KKM), Dehra Dun, India

- MAPAL, Myanmar

- MORHAN, Brazil

- NAPAL Sierra Leone

- PerMaTa, Indonesia

- Président de L'association Sénégalaise de Lutte Contre la Lèpre et les Maladies Tropicales Négligées (ASCL/MTN), Senegal

- Purple Hope Initiative Nigeria

- Rengesõ no Kai

- Sungai Buloh’s community, Selangor, Malaysia

Partner organizations consulted:

- The Leprosy Mission International's headquarters and regional offices in Myanmar, Bangladesh, India, Papua New Guinea, and Timor Leste

- The Leprosy Mission England and Wales

- The Leprosy Mission Trust India

\section{COVID-19 and Persons Affected by Leprosy: Recommendations for NGO and Govern- ment Leaders}

\section{Recommendations}

To address the needs and challenges faced by persons affected during the COVID-19 crisis, NGO and government leaders should:

(1) Implement swiftly and in a sustained manner relief actions in response to the humanitarian crisis faced by persons affected and their families worldwide.

(2) Develop and implement a participatory framework for humanitarian aid that links relief to development. Access an example of this kind of framework, "Participation by CrisisAffected Populations in Humanitarian Action: A Handbook for Practitioners."

(3) Support grassroots organizations of persons affected with funding and capacity building, and liaise with them to share information about COVID-19, existing national social schemes, and information for persons in the community about accessing fundamental rights.

(4) Support coalitions among grassroots organizations of persons affected with a view to elevating their joint voice at the international level and improve decision making, advocacy, and human rights enforcement.

(5) After mapping the disproportionate impact of COVID-19, map available solutions and resources. Such information needs to be available and accessible to persons affected and their representative organizations. 
(6) Ensure ethical standards in the use of images and information employed in fundraising strategies, including: ensuring informed consent; using positive images; presenting persons affected in a dignified manner that depicts them as agents rather than passive beneficiaries.

(7) Implement a gender approach to humanitarian aid that empowers women affected.

(8) Give due consideration to the social determinants of leprosy in the design of responses to the crisis in order to ensure access to healthcare. Extra-institutional barriers, such as lack of transportation to healthcare services, lack of income or dependency on third party authorization in the case of women, should also be taken into consideration.

(9) Liaise with and support National Leprosy Programmes to ensure access to the continuum of care for persons affected, including access to leprosy reaction treatment and the resumption of wound care services and self-care groups as soon as possible.

(10) Monitor the situation of former colonies and settlements and leprosy hospitals where COVID-19 patients are being treated in close proximity to elderly persons affected. 